\section{Age of Crime Onset and Psychopathic Traits in Female Juvenile Delinquents}

International Journal of Offender Therapy and Comparative Criminology 2014, Vol. 58(9) II0I-III9 (C) The Author(s) 2013

Reprints and permissions: sagepub.com/journalsPermissions.nav DOI: $10.1177 / 0306624 X 13489864$ ijo.sagepub.com

@SAGE

\author{
Pedro Pechorro', Rui Abrunhosa Gonçalves², \\ João Marôco ${ }^{3}$, Cristina Nunes ${ }^{4}$, and Saul Neves Jesus ${ }^{4}$
}

\begin{abstract}
The aim of this study was to analyze the role of psychopathic traits in the age of crime onset of female juvenile delinquents. Using a sample of 132 young females from the Juvenile Detention Centers of the Portuguese Ministry of Justice and from schools in the Lisbon region, a group of early crime onset $(n=44)$, a group of late crime onset $(n=44)$, and a nondelinquent school group $(n=44)$ were formed. Results showed that early crime onset participants score higher on psychopathy measures, self-reported delinquency, and crime seriousness than late crime onset participants and school participants. Psychopathic-traits scores were significantly associated with age of crime onset, age at first trouble with the law, and frequency and seriousness of crime.
\end{abstract}

\title{
Keywords
}

female juvenile delinquency, psychopathic traits, crime onset

The timing of the onset of antisocial behavior is one of the most critical pieces of information in understanding maladaptive behaviors, substance use, alcoholism, delinquency, and criminal justice system involvement. Antisocial behaviors that emerge during early and middle childhood are often harbingers of sustained antisocial behavior that persist through adolescence and endure into adulthood (DeLisi, Beaver, Wright, \& Vaughn, 2008; Vaughn \& Howard, 2005). Females below age 18 comprise one of the fastest growing segments of the juvenile-justice population, with their

\footnotetext{
IUniversity of Algarve, Faro, Portugal

2University of Minho, Braga, Portugal

3ISPA-Instituto Universitário, Lisboa, Portugal

${ }^{4}$ Research Center for Spatial and Organizational Dynamics of the University of Algarve, Faro, Portugal

Corresponding Author:

Pedro Pechorro, University of Algarve (UAlg), Campus de Gambelas, 8005-I39 Faro, Portugal.

Email: ppechorro@gmail.com
} 
arrests accounting for $27 \%$ of total arrests during 1999. Furthermore, delinquency cases involving adolescent females increased by 83\% between 1988 and 1997 (American Bar Association \& National Bar Association, as cited in Leve \& Chamberlain, 2004; Porter, 2000). In recent years, violence among young females has increased in terms of number of offences committed as well as the severity of these offences (Cauffman, Lexcen, Goldweber, Shulman, \& Grisso, 2007; Thomas, 2005).

Theoretical and empirical models describing the development of antisocial behavior in young adolescent girls have been scarce. Risk factors have been identified predominantly for males (Wong, Slotboom, \& Bijleveld, 2010). Not much is known about the precursors, etiological factors and correlates of female delinquency. This dearth of knowledge about developmental trajectories is partly due to the lower base rate of criminal activity among females relative to males, particularly at a young age. The relative lack of research on girls may also be a function of a lack of consensus on how to define and assess female antisocial behavior, with somewhat divergent approaches being taken within the fields of psychiatry, psychology and criminology (Hipwell et al., 2002).

Research has indicated that there are several common pathways leading to antisocial and aggressive behavior (Frick, 2012). Researchers who embrace the age of onset subtyping approach have identified two main groups of offenders: the early starters (Patterson, DeBaryshe, \& Ramsey, 1989) or life-course-persistent offenders (Loeber \& Stouthamer-Loeber, 1998; Moffitt, 1993), who commit their first transgression early and persist in offending throughout the life span; and the late starters (Patterson et al., 1989), adolescence-limited offenders (Moffitt, 1993), or limited duration offenders (Loeber \& Stouthamer-Loeber, 1998). Operational definitions of early onset of delinquent behavior generally tend to involve delinquency beginning before the age of 11 or 12 years (Parker \& Morton, 2009). Diagnostic and Statistical Manual of Mental Disorders (4th ed., text rev.; DSM-IV-TR; American Psychiatric Association [APA], 2000), taking into account that these age-of-onset distinctions have important implications, presents two subtypes of conduct disorder (CD) based on age of onset: childhood-onset type characterized by onset prior to age 10 and an adolescent-onset type characterized by onset after age 10 .

Psychopathic traits are associated with a variety of adverse outcomes in adolescence and adulthood. The psychopathy construct is characterized by a constellation of interpersonal (e.g., manipulation, deceit, egocentricity), affective (e.g., lack of empathy, remorse, or guilt), behavioral (e.g., irresponsibility, impulsivity), and antisocial (e.g., poor anger control, serious criminal behavior) traits (Hare, 2003, 2006). The construct is now well validated among adult males, and to a lesser extent, among adult females (Bolt, Hare, Vitale, \& Newman, 2004; Hare, 2003; Jackson, Rogers, Neumann, \& Lambert, 2002). There is, however, a controversial discussion about the feasibility of its downward extension to children and adolescents (Seagrave \& Grisso, 2002; Sevecke \& Kosson, 2010; Sevecke, Lehmkuhl, \& Krischer, 2009). The many investigations that have now been dedicated to adolescent psychopathy suggest support for the existence of similar correlates as seen in adult samples. For example, youth with higher psychopathic traits are generally more prone to use excessive and disproportioned violence in their crimes (Fritz, Wiklund, Koposov, Klinteberg, \& 
Ruchkin, 2008; Lindberg et al., 2009), and start engaging in criminal activities earlier in life, come into contact with the justice system earlier in life, and have higher frequency of delinquent behaviors (Pechorro et al., 2014).

Although there is growing evidence corroborating the utility of the psychopathy construct in adolescent males, very few studies have specifically addressed psychopathy in female youths. There is, however, some evidence that psychopathy is expressed differently in girls and women (Charles, Acheson, Mathias, Furr, \& Dougherty, 2012). A close examination of the studies that have investigated the role of psychopathic traits in female youths reveals that relatively small sample sizes of adjudicated girls are included. They have only constituted approximately $11 \%$ to $22 \%$ of the total sample (Frick, 1998; Frick, O’Brien, Wootton, \& McBurnett, 1994). We can conclude that, while psychopathic personality traits can be detected in female samples, it is still unclear whether psychopathy in girls has the same structure and behavioral correlates as psychopathy in boys. For example, Vincent, Vitacco, Grisso, and Corrado (2003) tried to identify subtypes of offenders based on the Psychopathy Checklist-Youth Version (PCL:YV), but although their sample consisted of 441 adolescents ( 326 boys, 115 girls), all girls were excluded from analysis due to the limited evidence for the validity of the PCL:YV in girls. Other studies have compared the prevalence of psychopathic traits between male and female juvenile offenders. For example, Pechorro et al. (2013) concluded that female juvenile offenders show less callous-unemotional (CU) traits, more emotional symptoms, more prosocial behaviors, less self-reported delinquent behavior, and lower crime seriousness.

Frick, Lilienfeld, Ellis, Loney, and Silverthorn (1999) have proposed a developmental trajectory to psychopathy, especially among youth with early onset conduct problems (Moffitt, 1993; Moffitt \& Caspi, 2001). These authors suggested that the antisocial behavior of youth scoring high on $\mathrm{CU}$ traits is qualitatively different from that of children or adolescents who exhibit conduct problems but not CU traits. In a series of studies, he has demonstrated that antisocial and aggressive behaviors of children who score high on $\mathrm{CU}$ traits are less strongly related to adversity factors, such as poor parenting or low intelligence, and more strongly related to thrill and adventure seeking (Frick, Kimonis, Dandreaux, \& Farrel, 2003), a reward-dominant response style, and deficits in processing negative emotional stimuli (Kimonis, Frick, Fazekas, \& Loney, 2006; Loney, Frick, Clements, Ellis, \& Kerlin, 2003).

Silverthorn and Frick (1999), after reviewing the limited available research on antisocial girls, suggested that a childhood-onset pathway and an adolescent-onset pathway cannot be applied to girls without some important modifications. These authors proposed that antisocial girls show a third developmental pathway which they labeled delayed-onset pathway. Their model assumes that many of the pathogenic mechanisms that may contribute to the development of antisocial behavior in girls, such as cognitive and neuropsychological deficits, a dysfunctional family environment, and/or the presence of a CU interpersonal style, could be present in childhood, but they do not lead to severe and overt antisocial behavior until adolescence. They proposed that the delayedonset pathway for girls is analogous to the childhood-onset pathway in boys and that there is no analogous pathway in girls to the adolescent-onset pathway in boys. 
According to Salekin (2006), it remains unclear how the phenomenon of psychopathy can be neatly accommodated within Moffitt's (1993) dual subtype scheme. Whereas it has been suggested that the early onset persistent offenders may be the prototype of young persons with psychopathic-like traits, there is evidence that these individuals do not fit neatly into this offender subgroup. According to Vincent et al. (2003), from a cluster analysis of the distinctive facets of the construct of psychopathy (i.e., affective, interpersonal, and behavioral), there may be more than the two distinctive juvenile offender subtypes.

Moffitt, Caspi, Harrington, and Milne (2002) reported comparisons on outcomes of males who participated in the Dunedin longitudinal study. The childhood-onset delinquents at age 26 years were the most elevated on psychopathic personality traits, mental-health problems, substance dependence, numbers of children, financial problems, work problems, and drug-related and violent crime, including violence against women and children. The adolescent-onset delinquents at 26 years were less extreme but elevated on impulsive personality traits, mental-health problems, substance dependence, financial problems, and property offenses. The findings supported the theory of life-course-persistent and adolescence-limited antisocial behavior in males.

Other authors have suggested that the presence of a $\mathrm{CU}$ interpersonal style may be an important marker along with the presence of impulsivity/hyperactivity and conduct problems. Specifically, it is this combination that according to Lynam $(1996,1998)$ forms a unique subgroup of fledgling psychopaths, that is, tomorrow's antisocial adults can be found among today's antisocial children. Barry et al. (2000) have also shown the presence $\mathrm{CU}$ traits as designating this group of young persons with psychopathic-like traits. The importance of CU traits in developmental pathways to severe antisocial behavior in children was demonstrated by Frick et al. (2003). Their findings revealed that the presence of $\mathrm{CU}$ traits in nonreferred children may designate a distinct, behaviorally dysregulated group of children with conduct problems that may have unique processes underlying their dysregulation that make them more similar to adults with psychopathy.

Differential relationships between CU traits and adjustment in boys $(n=116)$ and girls $(n=118)$ at risk for antisocial behavior were examined by Charles et al. (2012). Boys were generally rated higher on measures of CU traits, but these traits were more prominently related to adjustment problems among girls. These authors suggest that expression of psychopathic traits may have more negative effects on adjustment for girls than boys, and that $\mathrm{CU}$ traits may be impacting adjustment in girls by impairing interpersonal relationships.

There is some evidence that $\mathrm{CU}$ traits are most important for designating a distinct subgroup of antisocial youth (Caputo, Frick, \& Brodsky, 1999; Christian, Frick, Hill, Tyler, \& Frazer, 1997), but most definitions of psychopathy include several other dimensions, including impulsivity/irresponsibility and narcissism/grandiosity (Cooke, Michie, \& Hart, 2006). Young people with more severe manifestations of these traits reportedly commit a disproportionate amount of crime, appear unperturbed when confronted with the destructive nature of their behavior, and are more likely to reoffend or resist efforts at rehabilitation (Forth \& Burke, 1998; Salekin, Rogers, \& Ustad, 2001). 
Children and adolescents who display these hallmarks of psychopathic-like traits are also at particular risk of developing proactive aggression (Christian et al., 1997).

Forth, Hart, and Hare (1990) were the first to introduce the measurement of psychopathy in youth using a specially adapted version of the PCL-R (Hare, 1991) which ultimately led to the PCL:YV (Forth, Kosson, \& Hare, 2003). Other authors followed the lead and developed their own versions of instruments intended to measure child and adolescent psychopathy. Frick and Hare (1994/2001) developed the Antisocial Process Screening Device (APSD). Lynam (1998) developed the Child Psychopathy Scale (CPS), which was later modified by Spain, Douglas, Poythress, and Epstein (mCPS; 2004). Andershed, Kerr, Stattin, and Levander (2002) developed the Youth Psychopathic Traits Inventory (YPI). Other less used measures were also developed (e.g., Psychopathy Content Scale [PCS]; Murrie \& Cornell, 2002).

Findings for age of onset of criminal conduct and its association with psychopathy scores have been mixed. For example, Vincent et al. (2003) reported that male young offenders scoring high on the PCL:YV (Forth et al., 2003) received their first convictions at significantly younger ages than those scoring lower. Brandt, Kennedy, Patrick, and Curtin (1997) using modified PCL-R scores reported a significant correlation with age of first arrest. Furthermore, Salekin, Brannen, Zalot, Leistico, and Neumann (2006) found a negative association between age of onset of antisocial behavior and PCL:YV scores, although the association was not statistically significant. Kosson, Cyterski, Steuerwald, Neumann, and Walker-Matthews (2002), however, did not find a significant correlation with age at first trouble with the law and PCL:YV scores.

Adolescents with psychopathic traits tend to engage in more frequent offences and are more versatile in their offending. Campbell, Porter, and Santor (2004) found that PCL:YV scores were positively related with self-reported delinquency, aggressive behavior, and versatility of criminal history, although not related to official records for nonviolent and violent convictions. In a study of male adolescent probationers, Kosson et al. (2002) found the PCL:YV scores correlated $r=.27, r=.35$, and $r=.42$ with previous violent, nonviolent, and total charges. As well, Murrie, Cornell, Kaplan, McConville, and Levy-Elkon (2004) found that the PCL:YV correlated with adjudicated violent offense $\left(r_{p b}=.24\right)$ and with unadjudicated violent offense $\left(r_{p b}=.30\right)$. In addition, Vincent et al. (2003) reported that youth scoring higher on the PCL:YV have significantly more nonviolent and violent convictions than youth scoring lower.

With respect to self-report psychopathy scales (Lilienfeld \& Fowler, 2006), Skeem and Cauffman (2003) coded the institutional files of 160 male adolescent offenders for age of first contact with the police, and type and number of prior offenses. The YPI (Andershed et al., 2002) was not related to age at first contact $(r=.11)$, number of offenses $(r=-.09)$, or number of person-related offenses $(r=.12)$. In contrast, other researchers have reported an association between self-report psychopathy scales and criminal conduct. For example, Poythress, Dembo, Wareham, and Greenbaum (2006) examined the association between indices of criminal conduct and the YPI, and the self-report APSD (Frick \& Hare, 1994/2001 Muñoz \& Frick, 2007) in a sample of 165 male and female youth in a juvenile detention program. A self-report delinquency scale assessed whether the youth had committed 23 different delinquent behaviors in 
the past year and the age of onset of these behaviors. The YPI and the APSD were moderately correlated with indices of past-year offending (both scales correlated at $r=.44)$. The earliest age of onset for any delinquent behavior was correlated $(r=-.29$ for the APSD, and $r=-.28$ for the YPI total scores). In addition, Murrie et al. (2004) reported that $\operatorname{APSD}\left(r_{p b}=.22\right)$ and Millon Adolescent Clinical Inventory (MACI; $r_{p b}=$ .18) scores were associated with whether the youth had been adjudicated for a violent offense.

Muñoz and Frick (2007) investigated the association between self-report APSD scores and antisocial behaviors in a community sample of 91 young adolescents. Parental and youth self-report APSD scores, self-reported delinquency, parent-rated conduct problems, and occurrence of police contacts were studied annually across 3 years. Within each of these time periods, self-report APSD was related to self-reported delinquency $(r=.58, r=.42$, and $r=.38)$ and police contacts $\left(r_{p b}=.25, r_{p b}=.34\right.$, and $\left.r_{p b}=.29\right)$. Parental APSD was related to parent-reported conduct problems $(r=.25, r$ $=.34$, and $r=.55)$ but not to the occurrence of police contacts $\left(r_{p b}=.11, r_{p b}=.08\right.$, and $\left.r_{p b}=.16\right)$. With respect to predictive validity, self-report APSD scores at Time 1 predicted self-reported delinquency and violence at Time $3(r=.50$, and $r=.43)$, and parent-reported conduct problems and aggression $(r=.62$, and $r=.47)$.

The investigation of age of criminal onset and juvenile psychopathy is considered an important area of study, but there is a lack of research on this topic, especially in European samples and especially regarding to females. To our knowledge this is the first study examining age of criminal onset and juvenile psychopathic traits in Portuguese female adolescents. By examining a sample of adolescent females from Portuguese juvenile detention centers and schools we hope to demonstrate that the age of crime onset is significantly related to psychopathic personality traits, self-reported delinquency, and crime seriousness. The present study was designed to test two hypotheses:

Hypothesis 1: Early crime onset participants will have higher average scores on the psychopathy measures, self-reported delinquency, and crime seriousness than late crime onset participants and school participants.

Hypothesis 2: Psychopathic-traits scores are significantly associated with age of crime onset, age at first trouble with the law, and frequency and seriousness of crime.

\section{Method}

\section{Participants}

The final sample consisted of 132 female participants recruited from a forensic context and a school context. It was subdivided to form the early crime onset group $(n=44$; $M=15.45$ years; $S D=1.17$ years; range $=14-18$ years $)$, the late crime onset group $(n=$ $44 ; M=15.86$ years; $S D=1.23$ years; range $=13-18$ years $)$, and the school group $(n=$ $44 ; M=15.77$ years; $S D=1.26$ years; range $=13-18$ years). The criterion used to form 
Table I. Frequency of Participants by Age of Onset Group.

\begin{tabular}{lcccc}
\hline & Early onset & Late onset & School group & $n$ \\
\hline Forensic sample & 44 & 44 & 0 & 88 \\
School sample & 0 & 0 & 44 & 44 \\
Total sample & 44 & 44 & 44 & 132 \\
\hline
\end{tabular}

the early crime onset and the late crime onset groups (early onset $\leq 12$ years; late onset $>13$ years) was based on official records and the self-reported age of crime onset.

Table 1 shows data regarding the frequency of participants per group.

\section{Instruments}

The APSD-Self-Report (APSD-SR; Caputo et al., 1999; Frick \& Hare, 2001; Muñoz $\&$ Frick, 2007) is a multidimensional 20 -item measure designed to assess psychopathic traits in adolescents modeled after the PCL-Revised (PCL-R; Hare, 2003). Each item is scored on a 3-point ordinal scale $(0=$ never, $1=$ sometimes, $2=$ often $)$. Higher scores mean an increased presence of the traits in question. The total score, as well as each dimension's score, is obtained by adding the respective items. Some studies (e.g., Frick et al., 1994) reported two main factors: CU traits (tapping interpersonal and affective dimensions of psychopathy, such as lack of guilt and absence of empathy) and an impulsivity/conduct problems (I-CP) factor (tapping behavioral aspects of conduct problems and impulse control problems). Other studies (e.g., Frick, Barry, \& Bodin, 2000) reported three main factors: CU traits factor and an I-CP factor which is subdivided into two further factors, namely, narcissism (Nar) and impulsivity (Imp). Higher scores indicate an increased presence of the characteristics associated with each factor. The Portuguese validation of the APSD self-report (Pechorro, 2011; Pechorro, Marôco, Poiares, \& Vieira, 2013) that was used demonstrated psychometric properties that justify its use with Portuguese youths in terms of factor structure, internal consistency, temporal stability, convergent and divergent validity, and concurrent validity. The internal consistency for the present study $(n=132)$, estimated by Cronbach's alpha, was as follows: APSD-SR total $=.82 ; \mathrm{I}-\mathrm{CP}=.84$; and $\mathrm{CU}=.55$. The result regarding the $\mathrm{CU}$ dimension was low, but still acceptable for exploratory research purposes (DeVellis, 1991).

The Child and Adolescent Taxon Scale (CATS; Harris, Rice, \& Quinsey, 1994; Quinsey, Harris, Rice, \& Cormier, 2006) is an actuarial rating scale developed from variables related to childhood and adolescent antisocial and aggressive characteristics (e.g., childhood aggression problem, arrested below the age of 16). This scale has eight items scored either "no" (0) or "yes" (1). The total score is obtained by adding the items. Higher scores mean higher psychopathic characteristics. Because CATS is an actuarial scale, no internal consistency reliability was estimated. Correlation with APSD-SR for the present study was $r=.54(p<.001)$. Interrater reliability was estimated using intraclass correlation coefficient $(\mathrm{ICC}=.97 ; p<.001)$. 
The Adapted Self-Reported Delinquency Scale (ASRDS; Carroll, Durkin, Houghton, \& Hattie, 1996; Carroll, Houghton, Durkin, \& Hattie, 2009) is a self-report measure consisting of 38 items, which assesses adolescent involvement in illegal and antisocial activities. The ASRDS score can be obtained by adding the items from a 3 -point ordinal scale $(0=$ never, $1=$ sometimes, $2=$ often $)$, where higher scores signify greater involvement in criminal activities. The ASRDS version validated for the Portuguese population (Pechorro, 2011) was used. ASRDS internal consistency for the present study, estimated by Cronbach's alpha, was .94 .

The Marlowe-Crowne Social Desirability Scale (MCSDS; Crowne \& Marlowe, 1960) short composite (MCSDS-SF) version was designed by Ballard (1992) from the original Marlowe-Crowne scale. It is recognized as a composite subscale and is currently probably the most used of all the subscales that have been derived from the original MCSDS. A Portuguese version of the MCSDS-SF, especially translated and adapted for adolescents, was used (Pechorro, 2011). Higher scores mean higher social desirability. Internal consistency for the present study, using a 12-item version of the MCSDS-SF scored either "no" (0) or "yes" (1), estimated by Kuder-Richardson coefficient was .60 . Such a result is low, but still acceptable for exploratory research purposes (DeVellis, 1991).

The Index of Crime Seriousness (ICS; Wolfgang, Figlio, Tracey, \& Singer, 1985, as cited in White et al., 1994) was used to determine the delinquency seriousness classification of official reports. Level 1 consisted of minor delinquency committed at home, such as stealing minor amounts of money from mother's purse. Level 2 consisted of minor delinquency outside the home, including shoplifting something worth less than i5, vandalism, and minor fraud (e.g., not paying bus fare). Level 3 consisted of moderately serious delinquency such as any theft more than i5, gang fighting, carrying weapons, and joyriding. Level 4 consisted of serious delinquency such as car theft and breaking and entering. Level 5 consisted of having performed at least two of each of the behaviors in the previous level. Higher levels mean higher crime seriousness. Interrater reliability for the present study was estimated using Kendall's tau-b (tau $=.94 ; p<.001)$.

In addition, a questionnaire was constructed to describe the sociodemographic and criminal characteristics of the participants and to analyze the possible moderating effect of these variables. This questionnaire includes questions about participants' age, nationality, ethnic group, rural versus urban origin, level of schooling completed, socioeconomic status, parents' marital status, nationality, number of siblings/half-siblings, taking of psychiatric drugs, age of first transgression, age of first problem with the law, and age of first incarceration in a Juvenile Detention Center. Socioeconomic status was measured by a combination of the parents' level of education and profession, appropriate to the Portuguese reality (Simões, 1994). Age of first problem with the law was defined as the age of the first intervention by the police (e.g., age of first arrest by the police, age of first crime charge).

\section{Procedures}

The age range for female youth participation in the study was previously set between 12 and 20 years because this is the age range when young people are amenable to 
interventions under the Portuguese judicial system's Educational Guardianship Act (Lei Tutelar-Educativa). Even though girls are not often admitted to the Portuguese Juvenile Detention Center (Centros Educativos), we chose to use only female participants due to the relative scarcity of studies done internationally. The questionnaires were individually applied to the youths by the first author of this study. The author who did the diagnosis of DSM-IV-TR CD (APA, 2000) did not know the subsequent grouping of the participants into early or late onset groups. Each questionnaire was preceded by an informed consent form, in which participants were informed of the voluntary and confidential nature of participation in the study. Parental informed consent was not needed due to the fact that the participants were under the Portuguese judicial system Educational Guardianship Act.

Collection of questionnaires in the forensic context was carried out individually after obtaining authorization from the General Directorate of Reintegration and Prison Services-Ministry of Justice (Direção-Geral de Reinserção e Serviços PrisionaisMinistério da Justiça). All the detainees from the six existing Juvenile Detention Centers managed by the Portuguese Ministry of Justice were informed about the nature of the study and asked to participate. The participation rate was around $92 \%$. Not all detainees agreed or were able to participate. Reasons included refusal to participate $(6 \%)$, inability to participate due to not understanding the language $(1 \%)$, and inability to participate due to security issues (1\%). The first author of this study clarified any questions that arose regarding participation. No incentives to encourage participation were given. All questionnaires of those who participated were appropriately completed. As there was a very high participation rate, corresponding to the large majority of the Portuguese juvenile inmate population detained at that moment in time, there was little or no selection bias present.

The collection of questionnaires in the school context took place after having obtained permission from the Directorate General of Education-Ministry of Education (Direção-Geral de Educação-Ministério da Educação) and from the parents of the participants. Twelve elementary/secondary schools from the greater Lisbon areas were randomly selected, of which 4 agreed to participate. Reasons for nonparticipation included the systematic absence of a response to collaboration requests made, alleged internal school organization issues that made collaboration impossible, as well as the refusal to collaborate due to the forensic content of the questionnaire. The schools that accepted to participate requested that participation of each student should be previously authorized by written consent, signed by their parent/guardian. In the end, about $17 \%$ of participants were excluded due to not belonging to the age range established or to reasons such as returning incomplete, blank, or illegible questionnaires.

Questionnaire data that were considered valid (e.g., appropriately completed by participants within the selected age range) were analyzed using SPSS v.20 (IBM SPSS, 2011). Following data entry, $10 \%$ of questionnaires were randomly selected to evaluate the quality of their entry. The quality was considered very good as practically no entry errors were detected. Then the early crime onset and the late crime onset groups were formed (early onset $\leq 12$ years; late onset $>13$ years). For the purposes of this study, the criterion used to form these groups was based on official records and the self-reported age of crime onset. Youths who reported to have committed a criminal 
offense or who were first formally charged with an offense at or before the age of 12 were considered early onset delinquents, while youths who reported to have committed a criminal offense or were first charged with an offense at age 13 or after were considered late onset delinquents.

MANOVA was used to analyze the multiple dependent variables together. Because homogeneity of variance/covariance assumption was not met (Box's $M=233.983 ; p<$ $.001)$ and group sizes were identical, the appropriate multivariate statistic was used. Univariate ANOVAs were used to compare groups when the assumptions of normality (skewness and kurtosis between -2 and 2) and homogeneity of variance were validated. Welch's ANOVA was used when the assumptions of normality were validated but the group variances revealed heteroscedasticity. For the post hoc multiple comparisons, Tukey HSD (honestly significant difference) was used when the assumptions of normality and homoscedasticity were validated, while Games-Howell test was used when group's variances revealed heteroscedasticity. Kruskal-Wallis test was used when the variables were ordinal or when the data clearly violated the assumption of normality and homogeneity of variance (Tabachnick \& Fidell, 2007). For the post hoc multiple comparisons, Mann-Whitney tests were used. The chi-square test was used to compare nominal variables. Point biserial correlations were used to analyze the association between nominal dichotomous variables and scale variables. Spearman's Rho was used to analyze associations between ordinal variables. Pearson's $r$ was used to analyze correlations between scale variables. Results were considered significant if $p<.05$ and marginally significant if $p<.1$ (Aron, Coups, \& Aron, 2013).

Effect size and power calculations were made (as described in Marôco, 2011), and the following values were obtained: APSD-SR I-CP (effect size $\eta_{p}^{2}=.37$; power $=1$ ), APSD-SR CU $\left(\eta_{p}^{2}=.28\right.$; power $\left.=1\right)$, CATS $\left(\eta_{p}^{2}=.85\right.$; power $\left.=1\right)$, ASRDS $\left(\eta_{p}^{2}=.50\right.$; power $=1)$, ICS $\left(\eta^{2}=.50\right.$; power $\left.=.95\right)$, and MCSDS-SF $\left(\eta_{p}^{2}=.09\right.$; power $\left.=.87\right)$. Most of these effect sizes values can be considered medium $[.05, .25]$ to large $[.25, .50]$, and the power values are considered good [.08, 1] (Marôco, 2011; Tabachnick \& Fidell, 2007).

\section{Results}

In the initial phase of data treatment, variables of the sociodemographic questionnaire between the three groups were analyzed. No statistically significant differences were found between the three groups regarding age $(F=1.365 ; p=.259)$, socioeconomic status $\left(\chi^{2}{ }_{\mathrm{KW}}=1.411 ; p=.507\right)$, ethnicity $\left(\chi^{2}=3.462 ; p=.218\right)$, rural versus urban origin $\left(\chi^{2}=2.015 ; p=1.0\right)$, and taking of psychiatric drugs $\left(\chi^{2}=3.667 ; p=.210\right)$. Results showed statistically significant differences between the groups regarding level of schooling completed $(F=83.480 ; p<.001)$; Tukey HSD post hoc tests revealed statistically significant differences between the school group and the early onset group $(p<.001)$ and between the school group and the late onset group $(p<.001)$. Number of siblings/half-siblings also differed significantly between groups $(F=10.721 ; p<$ $.001)$; statistically significant differences occurred between the school group and the early onset group $(p<.001)$ and between the early onset group and the late onset group 
$(p<.01)$. Parents' marital status also differed between groups $\left(\chi^{2}=32.896 ; p<.001\right)$, namely, between the school group and the early onset group $\left(\chi^{2}=8.055 ; p<.05\right)$, between the school group and the late onset group $\left(\chi^{2}=28.376 ; p<.001\right)$ and between the early onset group and the late onset group $\left(\chi^{2}=10.430 ; p<.05\right)$. Finally, the groups also differed in their nationality $\left(\chi^{2}=18.146 ; p<.01\right)$, namely, between the school group and the early onset group $\left(\chi^{2}=10.448 ; p<.01\right)$. The analysis of these variables demonstrated that the early onset group contained participants with lower level of schooling completed, whose parents were more often divorced/separated or deceased, who had more siblings/half-siblings, and more foreign nationals.

The results of the criminal variables between the early onset and the late onset groups were then analyzed. Results showed statistically significant differences between the groups regarding age of onset of criminal activities $(F=161.111 ; p<$ $.001)$, age of first problem with the law $\left(F_{\mathrm{W}}=63.945 ; p<.001\right)$, and age of first detention in a Juvenile Detention Center $(F=11.401 ; p<.001)$. Significant differences between the two groups were also found regarding $D S M-I V$-TR's (APA, 2000) CD diagnosis $\left(\chi^{2}=8.494 ; p<.01\right)$. The analysis of these variables between the early onset group and the late onset group revealed that the participants from the early onset group had their first problems with the law earlier in life, were younger when they were first incarcerated in a Juvenile Detention Center, and had proportionately more CD diagnosis $(95.5 \%$ vs. $72.7 \%)$.

A MANOVA was conducted to assess whether there were differences between the three groups (early crime onset group, late crime onset group, and school group) on a linear combination of dependent variables. The APSD-SR total score was not included as a dependent variable in this analysis due to perfect multicollinearity problems (Leech, Barrett, \& Morgan, 2008; Marôco, 2011). There were statistically significant differences in the dependent variables in at least two of the groups (Pillai's Trace = $1.249 ; F=34.678 ; p<.001 ; \eta_{p}^{2}=.625$; power $=1$ ). Follow-up univariate ANOVAs showed that statistically significant differences were found when comparing the three groups regarding the psychopathy measures (see Table 2).

Table 2 shows the significant differences found regarding the APSD-SR I-CP, APSD-SR CU, and CATS. Post hoc Games-Howell tests regarding the APSD-SR I-CP showed significant differences between the early onset group and the late onset group $(p<.001)$, between the early onset group and the school group $(p<.001)$, and between the late onset group and the school group $(p<.01)$. Post hoc Tukey HSD regarding the APSD-SR CU showed significant differences between the early onset group and the late onset group $(p<.001)$, and between the early onset group and the school group $(p<.001)$. Post hoc Games-Howell tests regarding the CATS, showed significant differences between the early onset group and the school group $(p<.001)$ and between the late onset group and the school group $(p<.001)$.

After comparing the three groups regarding the ASRDS, ICS, and MCSDS-SF, statistically significant differences were found as depicted in Table 3.

Post hoc Games-Howell tests regarding the ASRDS showed significant differences between the early onset group and the late onset group $(p=.02)$, between the early onset group and the school group $(p<.001)$ and between the late onset group and the 
Table 2. Descriptive Statistics and ANOVA Tests for the Psychopathy Measures by Age of Onset Group.

\begin{tabular}{|c|c|c|c|c|}
\hline & Early onset & Late onset & School group & $F$ and $p$ value ${ }^{a}$ \\
\hline APSD-SR I-CP & & & & $F_{W}=28.909$ \\
\hline$M(S D)$ & $12.55(5.78)$ & $7.18(3.19)$ & $4.98(3.20)$ & $p<.001$ \\
\hline APSD-SR CU & & & & $F=25.234$ \\
\hline$M(S D)$ & $5.09(2.13)$ & $3(1.73)$ & $2.55(1.45)$ & $p<.001$ \\
\hline CATS & & & & $F_{W}=564.499$ \\
\hline$M(S D)$ & 6.41 (1.55) & $6.11(1.26)$ & $0.36(.61)$ & $p<.001$ \\
\hline
\end{tabular}

Note. APSD = Antisocial Process Screening Device-Self-Report; I-CP = impulsivity-conduct problems dimension; $F_{\mathrm{W}}=$ Welch's ANOVA; $C U$ = callous-unemotional dimension; $C A T S=$ Child and Adolescent Taxon Scale. aANOVA.

Table 3. Descriptive Statistics, ANOVA and Kruskal-Wallis Tests for the Delinquency, Criminal, and Social Desirability Measures by Age of Onset Group.

\begin{tabular}{|c|c|c|c|c|}
\hline & Early onset & Late onset & School group & $\begin{array}{c}F \text { or } \chi^{2}{ }_{\mathrm{KW}} \text { and } \\
p \text { value }^{\mathrm{a}}\end{array}$ \\
\hline ASRDS & & & & $F_{W}=102.054$ \\
\hline$M(S D)$ & $25.82(12.11)$ & $19.52(9.14)$ & $4.60(3.52)$ & $p<.001$ \\
\hline ICS & & & & $\chi^{2}{ }_{K W}=65.930$ \\
\hline$M R(I R)$ & $94.02(2)$ & $73.42(1)$ & $32.06(0)$ & $p<.001$ \\
\hline MCSDS-SF & & & & $F_{W}=6.863$ \\
\hline$M(S D)$ & I7.57 (1.78) & I8.82 (2.05) & $19.02(2.50)$ & $p<.01$ \\
\hline
\end{tabular}

Note. ASRDS $=$ Adapted Self-Report Delinquency Scale; $F_{W}=$ Welch's ANOVA; ICS $=$ index of crime seriousness; $\chi^{2} K W=$ Kruskal-Wallis; $M R=$ Mean Rank; $I R=$ Interquartile Range; MCSDS-SF = MarloweCrowne Social Desirability Scale-Short Form.

aANOVA or Kruskal-Wallis Test.

school group $(p<.001)$. Post hoc Mann-Whitney tests regarding the ICS showed significant differences between the early onset group and the late onset group ( $p<$ $.001)$, between the early onset group and the school group $(p<.001)$, and between the late onset group and the school group $(p<.001)$. Post hoc Games-Howell tests regarding the MCSDS-SF showed significant differences between the early onset group and the late onset group $(p=.008)$ and between the early onset group and the school group $(p=.007)$.

The correlation of the APSD-SR total score with the other measures and variables was also tested. Statistically significant correlations were found, namely, with CATS $(r=.54 ; p<.001)$, ASRDS $(r=.62 ; p<.001)$, ICS $\left(r_{\mathrm{s}}=.67 ; p<.001\right)$, MCSDS-SF $(r=-.29 ; p<.001), D S M-I V-T R$ 's CD diagnosis $\left(r_{\mathrm{pb}}=.63 ; p<.001\right)$, age of crime onset $(r=-.50 ; p<.001)$, age of first problem with the law $(r=-.34 ; p<.001)$, and age of first incarceration in a juvenile detention center $(r=-.19 ; p=.08)$. 


\section{Discussion}

The relation between age of criminal onset and female juvenile psychopathy is an important area of study that has not been sufficiently investigated. The aim of this study was to analyze the role of psychopathic traits in the age of crime onset of female juvenile delinquents. We hypothesized that early crime onset participants would have higher average scores on the psychopathy measures, self-reported delinquency, and crime seriousness than late crime onset participants and school participants, and that psychopathic-traits scores would be significantly associated with age of crime onset, age at first trouble with the law, and frequency and seriousness of crime.

Analysis of the sociodemographic variables allowed us to conclude that the early onset group contained participants with lower level of schooling completed, whose parents were more often divorced/separated or deceased, who had more siblings/halfsiblings, and more foreign nationals. Analysis of the criminal variables between the early onset group and the late onset group revealed that the participants from the early onset group had their first problems with the law (contacts with the police and the courts) earlier in life, and were also younger when they were first incarcerated in a Juvenile Detention Center. In addition, proportionately more participants of the early onset group (95.5\% vs. $72.7 \%$ ) were diagnosed with CD (DSM-IV-TR; APA, 2000).

In comparisons between the three groups regarding the psychopathy measures (namely, APSD-SR I-CP, APSD-SR CU, and CATS), the early onset group tended to obtain the highest scores followed by the late onset group. This evidence reinforces the literature that supports the consistent association of psychopathic-like traits with early crime onset in males and females. Like Moffitt et al. (2002), we found that earlier age of crime onset is generally accompanied by higher psychopathy traits. We are not stating that higher psychopathic traits trigger earlier age of onset, but these two variables may be reinforcing each other alongside other variables like negative life events, substance abuse, inadequate parenting, low attachment to school or having delinquent friends (Wong et al., 2010), to produce life-course-persistent female offenders.

In comparisons regarding self-reported delinquency and crime seriousness, the early onset group also obtained the highest scores, followed by the late onset group. These results support those obtained by Tolan and Thomas (1995) in their longitudinal study and are consistent with the review conducted by Krohn, Thornberry, Rivera, and Le Blanc (2001), in which these authors found that early onset offenders were 40 times more likely than late onset offenders to become habitual criminals and committed between $40 \%$ and $700 \%$ more criminal acts. Not only the early onset participants commit crimes more frequently but also commit more serious ones. These minors show the most severe antisocial behavior among the incarcerated youths.

In comparisons regarding social desirability, it may seem like the results are counterintuitive, as higher scores for social desirability could be expected in female youths with early onset and higher psychopathic traits (so as to try to portray more positive images of themselves). One should have in mind that some caution is advised in interpreting these values due to the low Kuder-Richardson coefficient. Lilienfeld and Fowler (2006) had already showed that psychopaths frequently report the presence of 
socially devalued characteristics, such as antisocial behaviors, hostility, and weak impulse control, reliably. Quite frequently, it is considered that psychopaths are supposedly more adept than nonpsychopaths at manipulating their questionnaire answers, but there is no solid and consistent empirical evidence that supports such a claim. Only a few specific clinical observations and studies (e.g., Ray et al., 2013) have demonstrated that psychopaths could have scores similar to those of students because they can in some degree manipulate social desirability measures.

Findings for the association of psychopathic traits with age of criminal onset and first trouble with the law were statistically significant, but only marginally significant for the age of first incarceration in a juvenile detention center. Our findings corroborate previous studies (e.g., Brandt et al., 1997; Salekin et al., 2006; Vincent et al., 2003). Findings regarding the association of psychopathic traits with the frequency of delinquent behaviors and seriousness of crimes showed strong correlations in line with previous studies (e.g., Brandt et al., 1997; Campbell et al., 2004), implying that young females with higher psychopathic traits display the most severe antisocial behavior.

Our investigation clearly supports a relation between psychopathy scores and criminal conduct in young females. However, we must highlight that not all minors who show severe antisocial behavior together with the diagnosis of CD should be considered to be potential psychopaths, such a classification should be reserved for a distinct subgroup after suitable assessment (Lynam, 1996). We must stress the importance of the psychopathy construct for the early identification of young people at potential high risk and for the rigorous assessment of young people who have already come into contact with the judicial system, thus promoting an empirically grounded basis to guide interventions.

Our study contributes to the research on age of crime onset and juvenile psychopathic traits in female European samples. This is the first study examining age of crime onset in a female sample of Portuguese youths. In addition, we hope to promote the investigation of psychopathic traits the Portuguese ethnic/cultural reality, which may help to identify unique etiological pathways in the development of antisocial behavior (Kotler \& McMahon, 2005). To design specific interventions for young persons at various points of their criminal trajectory, we need to fully understand how the early onset life-course-persistent and the late onset adolescent-limited offenders are different. Understanding the unique developmental patterns of each group may allow interventions to be designed that prevent or alter an individual's progression along the trajectory, whether it is their by choice or circumstance.

It is necessary to point out several limitations of our study. First, the use of selfreport measures on psychopathy was a limitation. Second, the low internal consistency of some scales and dimensions (e.g., MCSDS-SF, APSD-SR CU) were limitations in terms of reliability of measurement. Third, the fact that our study was cross-sectional limited the certainty about the differences in age of onset that were found. It is recommended that future research in this area should use rating scales (e.g., PCL:YV), measures that show better internal consistency, and longitudinal research methodology that allows the study of the participants over time regarding the stability of the traits. 


\section{Declaration of Conflicting Interests}

The author(s) declared no potential conflicts of interest with respect to the research, authorship, and/or publication of this article.

\section{Funding}

The author(s) disclosed receipt of the following financial support for the research, authorship, and/or publication of this article: This article was partially financed by Fundação para a Ciência e Tecnologia (FCT) of Portugal.

\section{References}

American Psychiatric Association. (2000). Diagnostic and statistical manual of mental disorders (4th ed., text rev.). Washington, DC: Author.

Andershed, H., Kerr, M., Stattin, H., \& Levander, S. (2002). Psychopathic traits in nonreferred youths: A new assessment tool. In E. Blaauw \& L. Sheridan (Eds.), Psychopaths: Current international perspectives (pp. 131-158). The Hague, Netherlands: Elsevier.

Aron, A., Coups, E., \& Aron, E. (2013). Statistics for psychology (6th ed.). New York, NY: Pearson.

Ballard, R. (1992). Short forms of the Marlowe-Crowne Social Desirability Scale. Psychological Reports, 71, 1155-1160.

Barry, C., Frick, P., DeShazo, T., McCoy, M., Ellis, M., \& Loney, B. (2000). The importance of callous-unemotional traits for extending the concept of psychopathy to children. Journal of Abnormal Psychology, 109, 335-340.

Bolt, D., Hare, R., Vitale, J., \& Newman, J. (2004). A multigroup response theory analysis of the Psychopathy Checklist-Revised. Psychological Assessment, 16, 155-168.

Brandt, J., Kennedy, W., Patrick, C., \& Curtin, J. (1997). Assessment of psychopathy in a population of incarcerated adolescent offenders. Psychological Assessment, 9, 429-435.

Campbell, M., Porter, S., \& Santor, D. (2004). Psychopathic traits in adolescent offenders: An evaluation of criminal history, clinical, and psychosocial correlates. Behavioral Sciences and the Law, 22, 23-47.

Caputo, A., Frick, P., \& Brodsky, S. (1999). Family violence and juvenile sex offending: The potential role of psychopathic traits and negative attitudes toward women. Criminal Justice and Behavior, 26, 338-356.

Carroll, A., Durkin, K., Houghton, S., \& Hattie, J. (1996). An adaptation of Mak's self-reported delinquency scale for western Australian adolescents. Australian Journal of Psychology, $48,1-7$.

Carroll, A., Houghton, S., Durkin, K., \& Hattie, J. (2009). Adolescent reputations and risk. New York, NY: Springer.

Cauffman, E., Lexcen, F., Goldweber, A., Shulman, E., \& Grisso, T. (2007). Gender differences in mental health symptoms among delinquent and community youth. Youth Violence and Juvenile Justice, 5, 287-307.

Charles, N., Acheson, A., Mathias, C., Furr, R., \& Dougherty, D. (2012). Psychopathic traits and their association with adjustment problems in girls. Behavioral Sciences \& the Law, 30, 631-642.

Christian, R. E., Frick, P. J., Hill, N. L., Tyler, L., \& Frazer, D. R. (1997). Psychopathy and conduct problems in children: II. Implications for subtyping children with conduct problems. Journal of the American Academy of Child \& Adolescent Psychiatry, 36, 233-241. 
Cooke, D., Michie, C., \& Hart, S. (2006). Facets of clinical psychopathy: Toward clear measurement. In C. J. Patrick (Ed.), Handbook of psychopathy (pp. 91-106). New York, NY: Guilford.

Crowne, D., \& Marlowe, D. (1960). A new scale of social desirability independent of psychopathology. Journal of Consulting Psychology, 24, 349-354.

DeLisi, M., Beaver, K., Wright, P., \& Vaughn, M. (2008). The etiology of criminal onset: The enduring salience of nature and nurture. Journal of Criminal Justice, 36, 217-223.

DeVellis, R. (1991). Scale development: Theory and applications. London, England: Sage.

Forth, A. E., \& Burke, H. C. (1998). Psychopathy in adolescence: Assessment, violence and developmental precursors. In D. J. Cooke, A. E. Forth \& R. D. Hare (Eds.), Psychopathy: Theory, research and implications for society (pp. 205-229). Boston, MA: Kluwer Academic.

Forth, A. E., Hart, S. D., \& Hare, R. D. (1990). Assessment of psychopathy in male young offenders. Psychological Assessment, 2, 342-344.

Forth, A., Kosson, D., \& Hare, R. (2003). The Psychopathy Checklist: Youth Version. Toronto, Ontario, Canada: Multi-Health Systems.

Frick, P. (1998). Conduct disorders and severe antisocial behaviour. New York, NY: Plenum.

Frick, P. (2012). Developmental pathways to conduct disorder: Implications for future directions in research, assessment, and treatment. Journal of Clinical Child \& Adolescent Psychology, 41, 378-389.

Frick, P., Barry, C., \& Bodin, S. (2000). Applying the concept of psychopathy to children: Implications for the assessment of antisocial youth. In C. Gacono (Ed.), The clinical and forensic assessment of psychopathy: A practitioner's guide (pp. 1-24). Mahwah, NJ: Lawrence Erlbaum.

Frick, P., \& Hare, R. (2001). Antisocial Process Screening Device (APSD): Technical manual. Toronto, Ontario, Canada: Multi-Health Systems. (Original work published 1994)

Frick, P. J., Lilienfeld, S. O., Ellis, M., Loney, B., \& Silverthorn, P. (1999). The association between anxiety and psychopathy dimensions in children. Journal of Abnormal Child Psychology, 27, 383-392.

Frick, P., Kimonis, E., Dandreaux, D., \& Farrel, J. (2003). The 4 year stability of psychopathic traits in non-referred youth. Behavioral Sciences \& the Law, 21, 713-736.

Frick, P., O’Brien, B., Wootton, J., \& McBurnett, K. (1994). Psychopathy and conduct problems in children. Journal of Abnormal Psychology, 103, 700-707.

Fritz, M., Wiklund, G., Koposov, R., Klinteberg, B., \& Ruchkin, V. (2008). Psychopathy and violence in juvenile delinquents: What are the associated factors? International Journal of Law and Psychiatry, 31, 272-279.

Hare, R. (1991). The Hare Psychopathy Checklist: Technical manual. Toronto, Ontario, Canada: Multi-Health Systems.

Hare, R. (2003). The Hare Psychopathy Checklist-Revised: Technical manual (2nd ed.). Toronto, Ontario, Canada: Multi-Health Systems.

Harris, G., Rice, M., \& Quinsey, V. (1994). Psychopathy as a taxon: Evidence that psychopaths are a discrete class. Journal of Consulting and Clinical Psychology, 62, 387-397.

Hipwell, A., Loeber, R., Stouthamer-Loeber, M., Keenan, K., White, H., \& Kroneman, L. (2002). Characteristics of girls with early onset disruptive and anti-social behaviour. Criminal Behaviour and Mental Health, 12, 99-118.

IBM SPSS. (2011). IBM SPSS Statistics Base 20. Chicago, IL: SPSS.

Jackson, R., Rogers, R., Neumann, C., \& Lambert, P. (2002). Psychopathy in female offenders: An investigation of its underlying dimensions. Criminal Justice and Behavior, 29, 692-704. 
Kimonis, E., Frick, P., Fazekas, H., \& Loney, B. (2006). Psychopathy, aggression, and the emotional processing of emotional stimuli in non-referred girls and boys. Behavioral Sciences \& the Law, 24, 21-37.

Kosson, D. S., Cyterski, T. D., Steuerwald, B. L., Neumann, C. S., \& Walker-Matthews, S. (2002). The reliability and validity of the Psychopathy Checklist: Youth Version (PCL:YV) in non-incarcerated adolescent males. Psychological Assessment, 14, 97-109.

Kotler, J., \& McMahon, R. (2005). Child psychopathy: Theories, measurement, and relations with the development and persistence of conduct problems. Clinical Child and Family Psychology Review, 8, 291-325.

Krohn, M., Thornberry, T., Rivera, C., \& Le Blanc, M. (2001). Later careers of very young offenders. In R. Loeber \& D. Farrington (Eds.), Child Delinquents: Development, interventions, and service needs (pp. 67-93). Thousand Oaks, CA: Sage.

Leech, N., Barrett, K., \& Morgan, G. (2008). SPSS for intermediate statistics: Use and interpretation (3rd ed.). New York, NY: LEA.

Leve, L., \& Chamberlain, P. (2004). Female juvenile offenders: Defining an early-onset pathway for delinquency. Journal of Child and Family Studies, 13, 439-452.

Lilienfeld, S., \& Fowler, K. (2006). The self-report assessment of psychopathy: Problems, pitfalls, and promises. In C. Patrick (Ed.), Handbook of psychopathy (pp. 107-132). New York, NY: Guilford.

Lindberg, N., Laajasalo, T., Holi, M., Putkonen, H., Weizmann-Henelius, G., \& HäkkänenNyholm, H. (2009). Psychopathic traits and offender characteristics - A nationwide consecutive sample of homicidal male adolescents. BMC Psychiatry, 9, Article 18.

Loeber, R., \& Stouthamer-Loeber, M. (1998). Development of juvenile aggression and violence: Some common misconceptions and controversies. American Psychologist, 53, 242-259.

Loney, B., Frick, P., Clements, C., Ellis, M., \& Kerlin, K. (2003). Callous-unemotional traits, impulsivity, and emotional processing in adolescents with antisocial behavior problems. Journal of Clinical Child \& Adolescent Psychology, 32, 66-80.

Lynam, D. (1996). Early identification of chronic offenders: Who is the fledgling psychopath? Psychological Bulletin, 120, 209-243.

Lynam, D. (1998). Early identification of the fledgling psychopath: Locating the psychopathic child in the current literature. Journal of Abnormal Psychology, 107, 566-575.

Marôco, J. (2011). Análiseestatística com o SPSS Statistics [Statistical analysis with SPSS Statistics]. Pero Pinheiro, Portugal: ReportNumber.

Moffitt, T. (1993). Adolescent-limited and life-persistent antisocial behaviour: A developmental taxonomy. Psychological Review, 100, 674-701.

Moffitt, T., \& Caspi, A. (2001). Childhood predictors differentiate life-course persistent and adolescent-limited antisocial pathways among males and females. Development and Psychopathology, 13, 355-375.

Moffitt, T., Caspi, A., Harrington, H., \& Milne, B. (2002). Males on the life-course persistent and adolescent-limited antisocial pathways: Follow-up at age 26. Development and Psychopathology, 14, 179-206.

Muñoz, L., \& Frick, P. (2007). The reliability, stability, and predictive utility of the self-report version of the antisocial process screening device. Scandinavian Journal of Psychology, 48, 299-312.

Murrie, D., \& Cornell, D. (2002). Psychopathy screening of incarcerated juveniles: A comparison of measures. Psychological Assessment, 14, 390-396.

Murrie, D., Cornell, D., Kaplan, S., McConville, D., \& Levy-Elkon, A. (2004). Psychopathy scores and violence among juvenile offenders: A multi-measure study. Behavioral Sciences \& the Law, 22, 49-67. 
Parker, J., \& Morton, T. (2009). Distinguishing between early and late onset delinquents: Race, income, verbal intelligence and impulsivity. North American Journal of Psychology, 11, 273-284.

Patterson, G. R., DeBaryshe, B. D., \& Ramsey, E. (1989). A developmental perspective on antisocial behavior. American Psychologist, 44, 329-335.

Pechorro, P. (2011). Juvenile delinquency: Study of some psychological and relational variables with an emphasis on psychopathic traits (Unpublished doctoral dissertation). Faculdade de Medicina da Universidade de Lisboa, Lisbon, Portugal.

Pechorro, P., Gonçalves, R., Marôco, J., Gama, A., Neves, S., \& Nunes, C. (2014). Juvenile delinquency and psychopathic traits: An empirical study with Portuguese adolescents. International Journal of Offender Therapy and Comparative Criminology, 58, 174-189. doi:10.1177/0306624X12465584

Pechorro, P., Marôco, J., Poiares, C., \& Vieira, R. (2013). Validation of the Portuguese version of the antisocial process screening device self-report with a focus on delinquent behavior and behavior problems. International Journal of Offender Therapy and Comparative Criminology, 57, 112-126.

Pechorro, P., Vieira, D., Poiares, A., Vieira, R., Marôco, J., Neves, S., \& Nunes, C. (2013). Psychopathy and behavior problems: A comparison of incarcerated male and female juvenile delinquents. International Journal of Law and Psychiatry, 36, 18-22.

Porter, G. (2000). Detention and delinquency cases, 1988-1997. Washington, DC: Office of Juvenile Justice and Delinquency Prevention.

Poythress, N. G., Dembo, R., Wareham, J., \& Greenbaum, P. (2006). Construct validity of the Youth Psychopathic Features Inventory (YPI) and the Antisocial Process Screening Device (ASPD) with justice involved adolescents. Criminal Justice and Behavior, 33, 26-55.

Quinsey, V., Harris, V., Rice, M., \& Cormier, C. (2006). Violent offenders: Appraising and managing risk (2nd ed.). Washington, DC: American Psychological Association.

Ray, J., Hall, J., Rivera-Hudson, N., Poythress, N., Lilienfeld, S., \& Morano, M. (2013). The relation between self-reported psychopathic traits and distorted response styles: A metaanalytic review. Personality Disorders: Theory, Treatment, and Research, 4, 1-14.

Salekin, R., Brannen, D., Zalot, A., Leistico, A., \& Neumann, C. (2006). Factor structure of psychopathy in youth: Testing the applicability of the new four-factor model. Criminal Justice and Behavior, 33, 135-157.

Salekin, R. T. (2006). Psychopathy in children and adolescents: Key issues in conceptualization and assessment. In C. J. Patrick (Ed.), Handbook of psychopathy (pp. 389-414). New York, NY: Guilford.

Salekin, R. T., Rogers, R., \& Ustad, K. (2001). Juvenile waiver to adult criminal courts: Prototypes for dangerousness, sophistication-maturity, and amenability to treatment. Psychology, Public Policy, and Law, 7, 381-408.

Seagrave, D., \& Grisso, T. (2002). Adolescent development and the measurement of juvenile psychopathy. Law and Human Behavior, 26, 219-239.

Sevecke, K., \& Kosson, D. (2010). Relationships of child and adolescent psychopathy to other forms of psychopathology. In R. Salekin \& D. Lynam (Eds.), Handbook of child and adolescent psychopathy (pp. 284-314). New York, NY: Guilford.

Sevecke, K., Lehmkuhl, G., \& Krischer, M. (2009). Examining relations between psychopathology and psychopathy dimensions among adolescent female and male offenders. European Child \& Adolescent Psychiatry, 18, 85-95. 
Silverthorn, P., \& Frick, P. (1999). Developmental pathways to antisocial behavior: The delayed-onset pathway in girls. Development and Psychopathology, 11, 101-126.

Simões, M. (1994). Investigação no âmbito da aferição nacional ao Teste das Matrizes Progressivas Coloridas de Raven (Unpublished doctoral dissertation). Faculdade de Psicologia e Ciências da Educação da Universidade de Coimbra, Coimbra, Portugal.

Skeem, J., \& Cauffman, E. (2003). Views of the downward extension: Comparing the Youth Version of the Psychopathy Checklist with the Youth Psychopathic Traits Inventory. Behavioral Sciences \& the Law, 21, 737-770.

Spain, S., Douglas, K., Poythress, N., \& Epstein, M. (2004). The relationship between psychopathic features, violence, and treatment outcome: The comparison of three youth measures of psychopathic features. Behavioral Sciences \& the Law, 22, 85-102.

Tabachnick, B., \& Fidell, L. (2007). Using multivariate statistics (5th ed.). New York, NY: Pearson.

Thomas, J. (2005). Youth Court Statistics 2003/2004. Juristat, 25(4), 1-19.

Tolan, P., \& Thomas, P. (1995). The implications of age of onset for delinquency risk: II. Longitudinal data. Journal of Abnormal Child Psychology, 23, 157-181.

Vaughn, M., \& Howard, M. (2005). The construct of psychopathy and its potential contribution to the study of serious, violent, and chronic youth offending. Youth Violence and Juvenile Justice, 3, 235-252.

Vincent, G., Vitacco, M., Grisso, T., \& Corrado, R. (2003). Subtypes of adolescent offenders: Affective traits and antisocial behavior patterns. Behavioral Sciences \& the Law, 21, 695-712.

White, J., Moffitt, T., Caspi, A., Jeglum-Bartusch, D., Needles, D., \& Stouthamer-Loeber, M. (1994). Measuring impulsivity and examining its relation to delinquency. Journal of Abnormal Psychology, 103, 192-205.

Wolfgang, M., Figlio, R., Tracy, P., \& Singer, S. (1985). The National survey of crime severity. Washington, DC: U.S. Department of Justice, Bureau of Statistics.

Wong, T., Slotboom, A., \& Bijleveld, C. (2010). Risk factors for delinquency in adolescent and young adult females: A European review. European Journal of Criminology, 7, 266-284. 